\title{
Purinergic and Adrenergic Agonists Synergize in Stimulating Vasopressin and Oxytocin Release
}

\author{
John R. Kapoor and Celia D. Sladek \\ Department of Physiology and Biophysics, Finch University of Health Sciences, The Chicago Medical School, North \\ Chicago, Illinois 60064
}

The A1 catecholamine neurons of the caudal ventrolateral medulla transmit hemodynamic information to the vasopressin (VP) neurons in the hypothalamus. These neurons corelease ATP with norepinephrine. Perifused explants of the hypothalamoneurohypophyseal system were used to investigate the role of these substances on VP release. ATP $(100 \mu \mathrm{M})$ increased VP release 1.5 -fold ( $p=0.027)$. The response was rapid but unsustained. It was blocked by the $\mathrm{P}_{2}$ receptor antagonist pyridoxal-phosphate6-azophenyl-2',4'-disulphonic acid (PPADS). The $\alpha_{1}$-adrenergic agonist phenylephrine (PE; $100 \mu \mathrm{M})$ also increased VP release by 1.5 -fold ( $p=0.014)$. Again, the response was rapid and unsustained. However, simultaneous perifusion of explants with ATP $(100 \mu \mathrm{M})$ and PE $(100 \mu \mathrm{M})$ resulted in a threefold to fourfold increase in VP release, which was sustained for as long as $4 \mathrm{hr}$. There was a similar synergistic effect of ATP and PE on oxytocin release. Interestingly, the synergistic response was delayed $\sim 40$ min relative to the response to either agent alone. Several experiments were performed to elucidate the cellular mechanisms of this synergism. The effect was blocked by PPADS, a protein kinase $\mathrm{C}$ inhibitor (bisindolylmaleimide I $\mathrm{HCl}$ ), and actinomycin, an inhibitor of gene transcription. These data suggest that $P_{2 x}$ receptor activation, PKC-mediated phosphorylation, and gene transcription are required for the synergistic response. The marked synergism of these coreleased agents is probably important to achieve sustained increases in plasma VP in response to prolonged hypotension. These observations may also have broad applications to CNS function, because ATP may be coreleased at noradrenergic synapses throughout the CNS.

Key words: norepinephrine; ATP; vasopressin; supraoptic nucleus; catecholamine; neurohypophysis; purinergic transmission; blood pressure regulation
Vasopressin (VP)-synthesizing neurons of the supraoptic and paraventricular nuclei (SON and PVN) receive direct, excitatory input from the A1 noradrenergic neurons of the caudal ventrolateral medulla (Alonso and Assenmacher, 1984; Day and Renaud, 1984; Day et al., 1984, 1992; Shioda et al., 1992; Ginsberg et al., 1994; Smith et al., 1995). In addition to norepinephrine (NE), various substances are colocalized or coreleased from the A1 neurons, including neuropeptide Y, substance P, and ATP (Everitt et al., 1984; Sawchenko et al., 1985; Blessing et al., 1986; Beroukas et al., 1989; Lundberg et al., 1989; Bittencourt et al., 1991; Sperlagh et al., 1998). Although abundant evidence supports the importance of the A1 pathway for stimulation of VP release in response to moderate decreases in blood pressure (Raby and Renaud, 1989; Smith et al., 1995), studies directed at demonstrating that NE is the primary transmitter mediating this response were not successful (Day et al., 1990). Adrenoceptor antagonists did not block A1 activation of VP cells, prompting the suggestion that these neurons use a substance other than NE as their principal transmitter (Day et al., 1990). In addition, injections of the broad-spectrum excitatory amino acid receptor antagonist kynurenic acid were ineffective in blocking excitation induced by stimulation of the A1 region, excluding the possibility that glutamate is responsible for VP cellular responses to A1 input (Day et al., 1990). A likely possibility is that colocalized, excitatory substances play a role in the regulation of VP release. The nucleotide ATP, which is commonly colocalized in catecholamine vesicles (Fried, 1980; Whittaker, 1982), may serve as a primary neurotransmitter to activate VP neurons in response to A1 input. A role for ATP in mediating responses to activation of the A1 pathway is supported by the finding that application of the

Received July 20, 2000; revised Sept. 7, 2000; accepted Sept. 11, 2000.

This work was supported by National Institutes of Health Grant R01-NS27975 to C.D.S. and by a grant-in-aid from Sigma Xi to J.R.K. The technical assistance of H. E. Sidorowicz is gratefully acknowledged.

Correspondence should be addressed to Dr. Celia D. Sladek, Department of Physiology, Chicago Medical School, 3333 Green Bay Road, North Chicago, IL 60064. E-mail: sladekc@finchcms.edu.

Copyright (C) 2000 Society for Neuroscience $0270-6474 / 00 / 208868-08 \$ 15.00 / 0$
$\mathrm{P}_{2}$ receptor blocker suramin $(10 \mathrm{~mm})$ in the $\mathrm{SON}$ reversibly blocked excitation of VP cells by A1 stimulation without preventing the excitatory effect of locally applied NE (Day et al., 1992). Histological and electrophysiological evidence demonstrating purinergic receptors on SON neurons further supports a role for purinergic transmission (Hiruma and Bourque, 1995; Shibuya et al., 1998).

Central catecholamine neurons have been studied for decades, and much is known about their contribution to the regulation of a variety of behavioral, autonomic, and endocrine functions. Little is known, however, about the functional consequences of noradrenergic-purinergic cotransmission in the CNS. In the periphery, ATP is known to function as a cotransmitter with $\mathrm{NE}$ in a number of tissues innervated by the sympathetic system (Burnstock, 1990; von Kugelgen and Starke, 1991). Central noradrenergic neurons might be expected to use similar cotransmission, especially as more evidence accumulates for the involvement of nonadrenergic neurotransmission (Gartside et al., 1995).

In the present investigation, perifused explants of the rat hypothalamoneurohypophyseal system (HNS) were used to study the role of ATP and NE in the regulation of VP and oxytocin release. Specifically, the effects of $\alpha_{1}$-adrenergic and purinergic receptor activation and the interactions of these agents were evaluated.

\section{MATERIALS AND METHODS}

Explant preparation. Male Sprague Dawley rats (125-149 gm) were obtained from Zivic-Miller. After decapitation, explants of the HNS were prepared as described previously (Sladek and Knigge, 1977). The brain and pituitary were removed from the skull using a caudal approach to maintain the pituitary stalk intact. The anterior pituitary was removed under a dissecting microscope. After gently removing the meninges (dura mater and arachnoid), a triangular block of tissue is removed from the ventral hypothalamus by cutting rostral to the optic chiasm, lateral to either side of the median eminence, and undercutting at a depth of 1-2 $\mathrm{mm}$. The explants included the magnocellular neurons of the supraoptic nucleus with their axonal projections extending through the median eminence and terminating in the neurohypophysis. By the use of a dissecting microscope, the explants were examined to insure that the neurohypophyseal stalk was intact. Also included in the explant are the suprachiasmatic, arcuate, and ventral portions of the ventromedial, preoptic, and periventricular nuclei as well as the organum vasculosum of the lamina terminalis. 
Perifusion conditions. Each explant is placed in a $500 \mu$ l perifusion chamber, maintained at $37^{\circ} \mathrm{C}$ in the multiple microchamber unit $(\mathrm{Cellex}$ Biosciences, Inc., Minneapolis, MN), and perifused with F12 nutrient mixture (Sigma, St. Louis, MO) fortified with $20 \%$ fetal calf serum, 1 $\mathrm{mg} / \mathrm{ml}$ glucose, $50 \mu \mathrm{U} / \mathrm{ml}$ penicillin, $50 \mu \mathrm{g} / \mathrm{ml}$ streptomycin, and $1 \times 10^{-4}$ $\mathrm{M}$ bacitracin. Bacitracin was added to the medium to prevent hormone degradation (Sladek and Armstrong, 1987). The final osmolality of the culture medium was $295-300 \mathrm{mosmol} / \mathrm{kg}$ of $\mathrm{H}_{2} \mathrm{O}$. The medium was warmed $\left(37^{\circ} \mathrm{C}\right)$ and gassed $\left(95 \% \mathrm{O}_{2}\right.$ and $\left.5 \% \mathrm{CO}_{2}\right)$ immediately before entering the explant chamber. Six explants were perifused simultaneously at a rate of $\sim 2.0 \mathrm{ml} / \mathrm{hr}$, and outflow from the chambers was collected individually in $20 \mathrm{~min}$ intervals using a six-place fraction collector that was kept in a refrigerator $\left(4^{\circ} \mathrm{C}\right)$ for subsequent measurement of $\mathrm{VP}$ or oxytocin (OT) concentration. Radioimmunoassay (RIA) was used to determine VP or OT concentration in these samples, and microvapor pressure osmometry (Wescor) was used to monitor osmolality of the perifusate.

Experimental design. Hormone release was allowed to stabilize for $4 \mathrm{hr}$ before exposure to any experimental conditions. During the subsequent time period, explants were perifused with basal medium or exposed to the indicated concentrations of ATP and/or PE (Sigma). Explants were exposed to antagonists [pyridoxal-phosphate-6-azophenyl-2', $4^{\prime}$-disulphonic acid (PPADS; Sigma); bisindolylmaleimide I, HCl (BI; Calbiochem, San Diego, CA); and actinomycin (Calbiochem)] $30 \mathrm{~min}$ before the addition of ATP. Most drugs were dissolved directly into the media. Exceptions are as follows: Actinomycin was dissolved in $50 \%$ ethanol, and $50 \mu \mathrm{l}$ of this stock solution was added to $50 \mathrm{ml}$ of medium. PE was added to media containing $0.03 \%$ vitamin $\mathrm{C}$ to ensure stability. Control explants were exposed to the same concentrations of solvents used to dissolve the drugs.

Radioimmunoassay. VP and OT concentrations in the perifusate were determined by RIA as described previously (Sladek et al., 1986; Yagil and Sladek, 1990). The antisera used were generated in conjunction with Arnel Products (Brooklyn, NY) and were used at a final dilution of 1:100,000. The buffer for both VP and OT assays was $0.1 \mathrm{~m}$ PBS, pH 7.6, with $1 \mathrm{mg} / \mathrm{ml}$ bovine serum albumin and $1 \mathrm{mg} / \mathrm{ml}$ sodium azide. Both assays were performed on 100 and $50 \mu \mathrm{l}$ aliquots of each fraction collected from each explant. The standards and samples were incubated for $72 \mathrm{hr}$ at $4^{\circ} \mathrm{C}$ in the presence of $5000 \mathrm{cpm}$ of ${ }^{125} \mathrm{I}$-arginine vasopressin or for $96 \mathrm{hr}$ at $4^{\circ} \mathrm{C}$ with $3500 \mathrm{cpm}$ of ${ }^{125}$ I-oxytocin (New England Nuclear). Ab-bound VP and OT were separated from free hormone with dextran-coated charcoal, and the amount of ${ }^{125} \mathrm{I}-\mathrm{VP}$ or ${ }^{125} \mathrm{I}-\mathrm{OT}$ in the pellet was determined with a gamma counter. The picograms per milliliter were obtained by comparing samples with a standard curve of known concentrations of either VP or OT. All samples from a given experiment were assayed at the same time. The minimum sensitivity was $1.0 \mathrm{pg} /$ tube for VP and $0.5 \mathrm{pg} /$ tube for OT.

Statistical analysis. As mentioned previously, each explant was allowed to equilibrate for $4 \mathrm{hr}$ before exposure to drugs. Basal hormone release was calculated for each explant as the mean hormone release at the end of this equilibration period. Hormone content is expressed as a percentage of this basal value. Results are expressed as the mean \pm SEM. Statistical significance was determined on $\log _{10}$-transformed data by ANOVA with repeated measures followed by a simple main effect analysis to establish specific group differences at individual time points. The level of significance was set to $p<0.05$.

\section{RESULTS}

\section{Effect of ATP on vasopressin release}

To determine whether ATP stimulates VP release from HNS explants and to identify the effective concentration of ATP, HNS explants were prepared as described above and placed in a perifusion chamber. Explants were either exposed to sequentially increasing concentrations of ATP $(10 \mu \mathrm{M}, 100 \mu \mathrm{M}$, and $1 \mathrm{~mm})$ at $2 \mathrm{hr}$ intervals or maintained in basal medium (control group). As shown in Figure 1, there was a significant increase in VP release in the ATP-treated explants $(F=5.684 ; p=0.0271)$. The 10 and $100 \mu \mathrm{M}$ doses of ATP stimulated VP release. However, the response to 100 $\mu \mathrm{M}$ ATP was not sustained throughout the $2 \mathrm{hr}$ exposure, nor was there a response to subsequent exposure to $1 \mathrm{mM}$ ATP. To determine further whether previous exposure to $10 \mu \mathrm{M}$ ATP limited the response to $100 \mu \mathrm{M}$ ATP and to identify the type of receptor activated by ATP, explants were exposed to $100 \mu \mathrm{M}$ ATP in the presence or absence of PPADS, an antagonist of the $\mathrm{P}_{2 \mathrm{x}}$ purinoceptor subtype (Lambrecht, 1996). As shown in Figure $2 A$, in the absence of PPADS, $100 \mu \mathrm{M}$ ATP elicited the fast and unsustained increase in VP release observed previously, but in the presence of PPADS, no increase in VP release was observed $(F=6.310 ; p=$ 0.0332 ). Thus, the response to $100 \mu \mathrm{M}$ ATP was similar regardless of whether explants were exposed to this dose initially or after exposure to $10 \mu \mathrm{M}$ ATP. Because $10 \mu \mathrm{M}$ PPADS had no significant effect on the basal release of VP (Fig. $2 B$ ), these data suggest that ATP acts at $\mathrm{P}_{2 \mathrm{X}}$ receptors to increase $\mathrm{VP}$ release from HNS

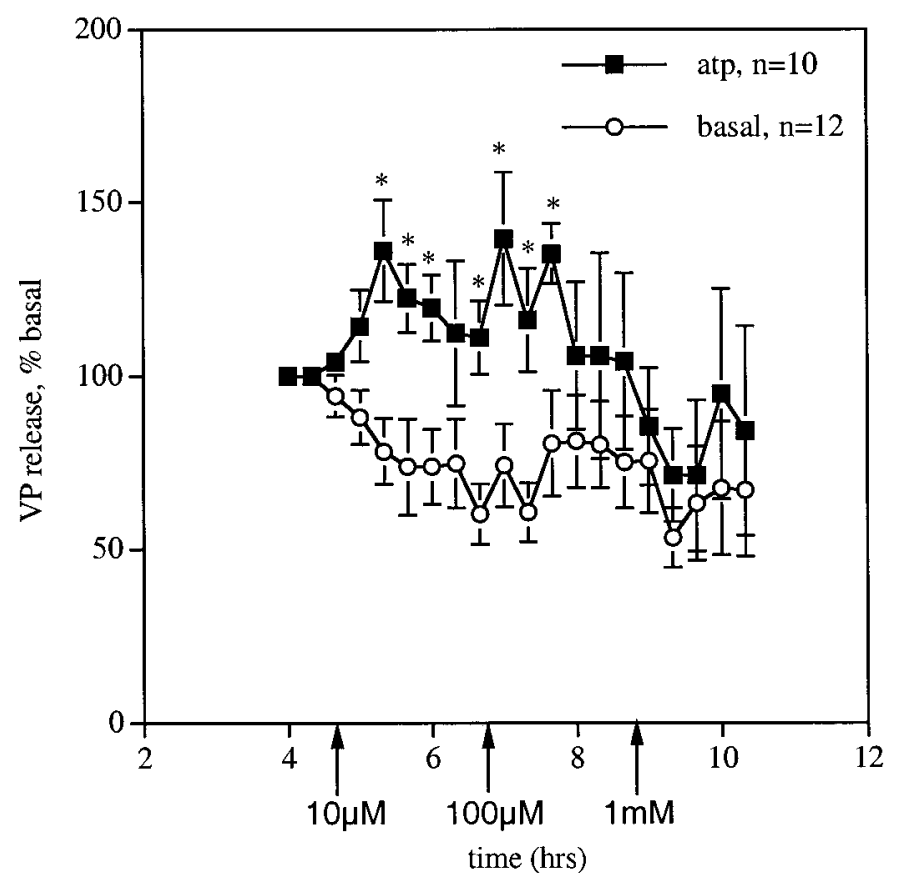

Figure 1. VP release from HNS explants in response to increasing concentrations of ATP $(10 \mu \mathrm{M}, 100 \mu \mathrm{M}$, and $1 \mathrm{mM})$. Explants were exposed to the respective concentrations of ATP beginning at the time indicated by the arrows. ATP stimulated VP release at the 10 and $100 \mu \mathrm{M}$ concentrations $\left({ }^{*} p<0.027\right)$. Basal release for ATP $(n=10)$ and time control $(n=12)$ groups was $142.2 \pm 35.6$ and $140.1 \pm 55.5 \mathrm{pg} / \mathrm{ml}$, respectively. atp, ATP.

explants. The decay in the response may reflect receptor desensitization or depolarization blockade, because in a separate group of explants the response to $100 \mu \mathrm{M}$ ATP was restored after a $2 \mathrm{hr}$ washout period (response to first and second ATP exposures, $167 \pm 16.2$ and $172 \pm 18 \%$, respectively; $n=6$ ).

\section{Effect of ATP on OT release}

Because ATP has been shown to act directly on nerve terminals in the neural lobe to increase VP but not OT release, the effect of ATP on OT release was evaluated to determine whether the effect of ATP on VP release reflected effects on stimulus-secretion coupling as opposed to action potential generation at the cell body. As shown in Figure 3, in the absence of PPADS, $100 \mu \mathrm{M}$ ATP elicited rapid and unsustained increases in OT release, but in the presence of PPADS, no increase in OT release was observed $(F=11.755$; $p=0.0075)$. As seen with VP, $10 \mu \mathrm{M}$ PPADS had no effect on the basal release of OT (data not shown). These data suggest that ATP acts at $\mathrm{P}_{2 \mathrm{X}}$ receptors to increase OT release from the explants. Because the reported effects of ATP on stimulus-secretion coupling in the neural lobe were limited to VP, these data suggest that ATP has actions in the hypothalamic portion of the explant to stimulate $\mathrm{VP}$ and OT release, in addition to actions at the nerve terminals.

\section{Effect of phenylephrine on VP and OT release}

$\mathrm{PE}$ was used to evaluate the effect of activation of $\alpha_{1}$-adrenergic receptors on $\mathrm{VP}$ release, because $\mathrm{NE}$ has been shown to either stimulate or inhibit VP neurons. This effect is dependent on the type of adrenergic receptor activated (Day et al., 1985; Sladek and Yagil, 1990). Exposure of HNS explants to 1, 10, and $100 \mu \mathrm{M} \mathrm{NE}$ did not significantly alter VP release when compared with a time control group (data not shown). Explants were exposed sequentially to 1,10 , and $100 \mu \mathrm{M}$ PE to determine the optimum concentration for stimulation of VP release. At 1 and $10 \mu \mathrm{M}, \mathrm{PE}$ was ineffective, but at $100 \mu \mathrm{M}, \mathrm{PE}$ increased VP release (data not shown). As shown in Figure 4, exposure of HNS explants initially to $100 \mu \mathrm{M}$ PE significantly increased VP release. The response was rapid and unsustained. ANOVA during the first hour of exposure to $\mathrm{PE}$ revealed a significant increase in $\mathrm{VP}$ release in the $\mathrm{PE}$ - 
A

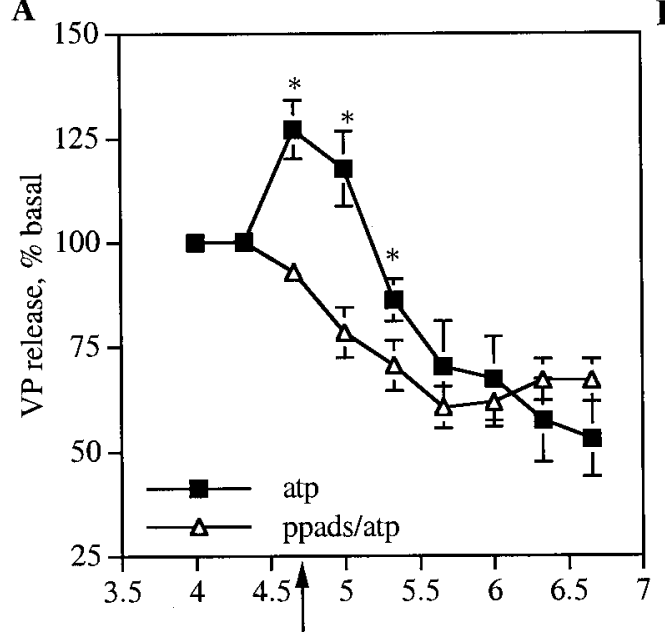

time (hrs)

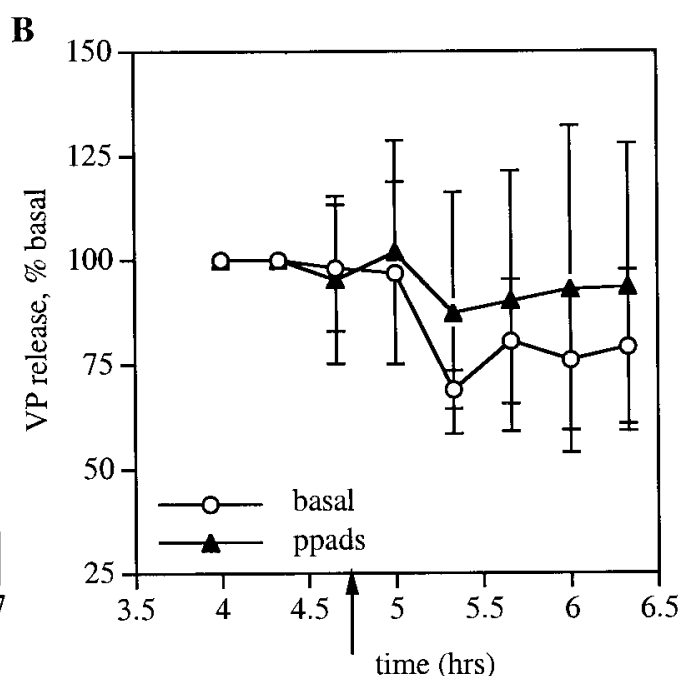

Figure 2. Inhibition of ATP stimulated VP release in the presence of PPADS. $A$, Addition of $10 \mu \mathrm{M}$ PPADS blocked the VP response to $100 \mu \mathrm{M}$ ATP $(F=6.310 ; p=0.0332)$. Explants were exposed to ATP beginning at the time indicated by the arrow. Basal release for ATP- $(n=5)$ and PPADS plus ATP-treated $(n=6)$ groups was $161 \pm 84$ and $130.6 \pm 27 \mathrm{pg} / \mathrm{ml}$, respectively $\left({ }^{*} p<0.05\right)$. B, PPADS $(10 \mu \mathrm{M}$; added at arrow) had no effect on the basal release of VP. Basal release for PPADS $(n=6)$ and time control $(n=6)$ groups was $50.7 \pm 23.8$ and $43.0 \pm 15.2 \mathrm{pg} / \mathrm{ml}$, respectively. ppads, PPADS.

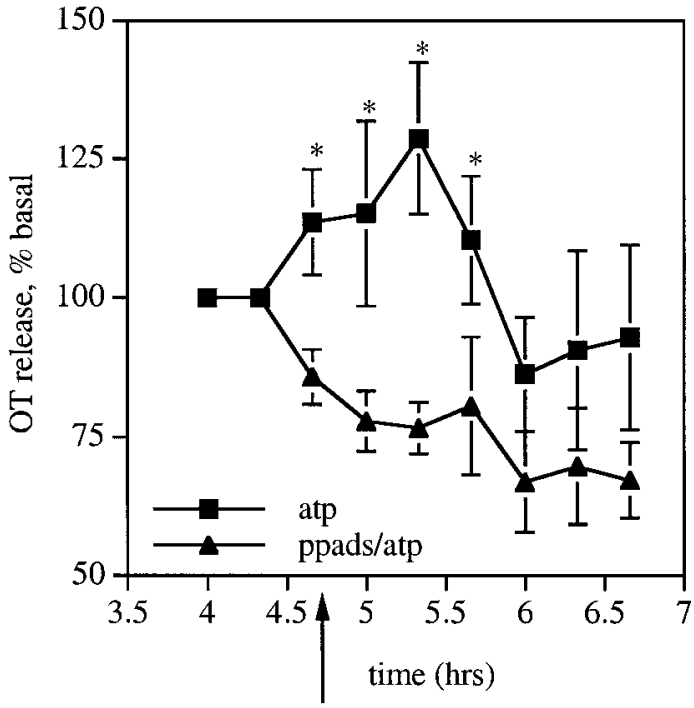

Figure 3. ATP stimulation of OT release is blocked by PPADS $(10 \mu \mathrm{M})$ $(F=11.755 ; p=0.0075)$. Explants were exposed to ATP beginning at the time indicated by the arrow. Basal release for ATP- $(n=5)$ and PPADS plus ATP-treated $(n=6)$ groups was $122.1 \pm 21.23$ and $164.4 \pm 28.02$ $\mathrm{pg} / \mathrm{ml}$, respectively $\left({ }^{*} p<0.05\right)$

treated explants $(F=7.522 ; p=0.0139)$. In contrast, PE did not significantly alter OT release (data not shown).

\section{Effect of combined exposure to ATP and PE on VP and OT release}

Subsequent experiments focused on the combined effect of ATP and PE on VP and OT release. As shown in Figure 5, simultaneous exposure of explants to $100 \mu \mathrm{M}$ ATP and $100 \mu \mathrm{M}$ PE resulted in synergistic responses that were delayed, larger, and sustained relative to the responses observed with ATP $(100 \mu \mathrm{M})$ or PE $(100 \mu \mathrm{M})$ individually. An overall ANOVA of the VP release data (Fig. $5 A$ ) revealed statistically significant differences in VP release between groups $(F=6.285 ; p=0.0048)$. Subsequent ANOVA comparing the ATP plus PE group with the ATP or the PE groups revealed a significant increase in VP release in the ATP plus PE-treated explants compared with explants exposed to ATP $(100 \mu \mathrm{M})(F=$ $5.58 ; p=0.0263)$ or PE $(100 \mu \mathrm{M})(F=5.528 ; p=0.0286)$. As

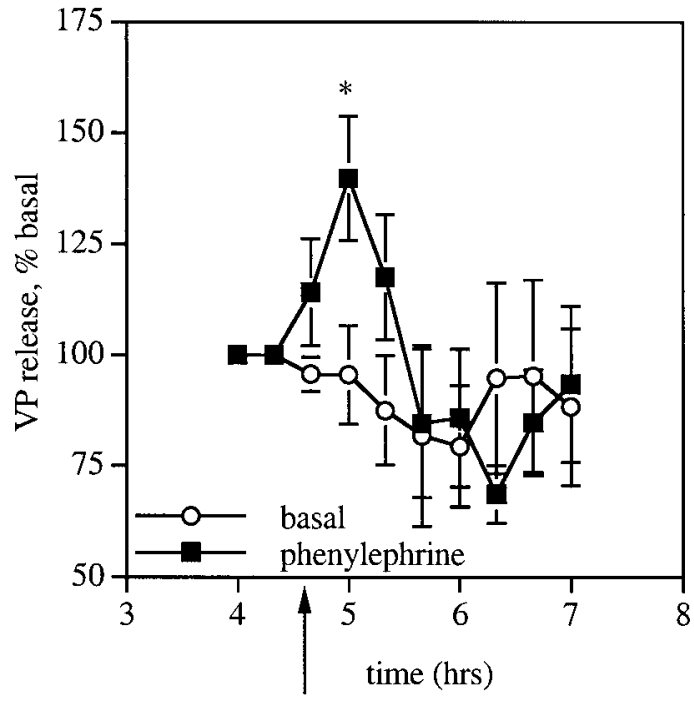

Figure 4. VP release in response to PE $(100 \mu \mathrm{M})$. Explants were exposed to $\mathrm{PE}$ beginning at the time indicated by the arrow. The response was fast and not sustained, similar to that elicited by ATP. Basal release for PE $(n=$ $11)$ and time control $(n=8)$ groups was $31.5 \pm 4.9$ and $38.9 \pm 12.4 \mathrm{pg} / \mathrm{ml}$, respectively $(* p<0.026)$.

Figure $5 B$ shows, OT release was comparably augmented by simultaneous exposure to ATP and PE. An overall ANOVA revealed statistically significant differences in OT release between groups $(F=18.862 ; p=0.0001)$. Subsequent ANOVA comparing the ATP plus PE group with the ATP or the PE groups revealed a significant increase in OT release in the ATP plus PE-treated explants compared with explants exposed to ATP $(100 \mu \mathrm{M})(F=17.135 ; p=$ $0.0007)$ or PE $(100 \mu \mathrm{M})(F=31.919 ; p<0.00001)$. The ability of ATP and PE to synergize in increasing OT release negates the possibility that the synergism is caused by ATP effects on stimulation secretion-coupling amplifying activation of $\alpha$-adrenergic receptors on the dendrites and/or perikarya, because ATP does not stimulate OT release from isolated neural lobe terminals (Troadec et al., 1998). These data suggest that the release of cotransmitters may be responsible for maintaining a sustained increase in plasma $\mathrm{VP}$ in response to decreased blood pressure. 


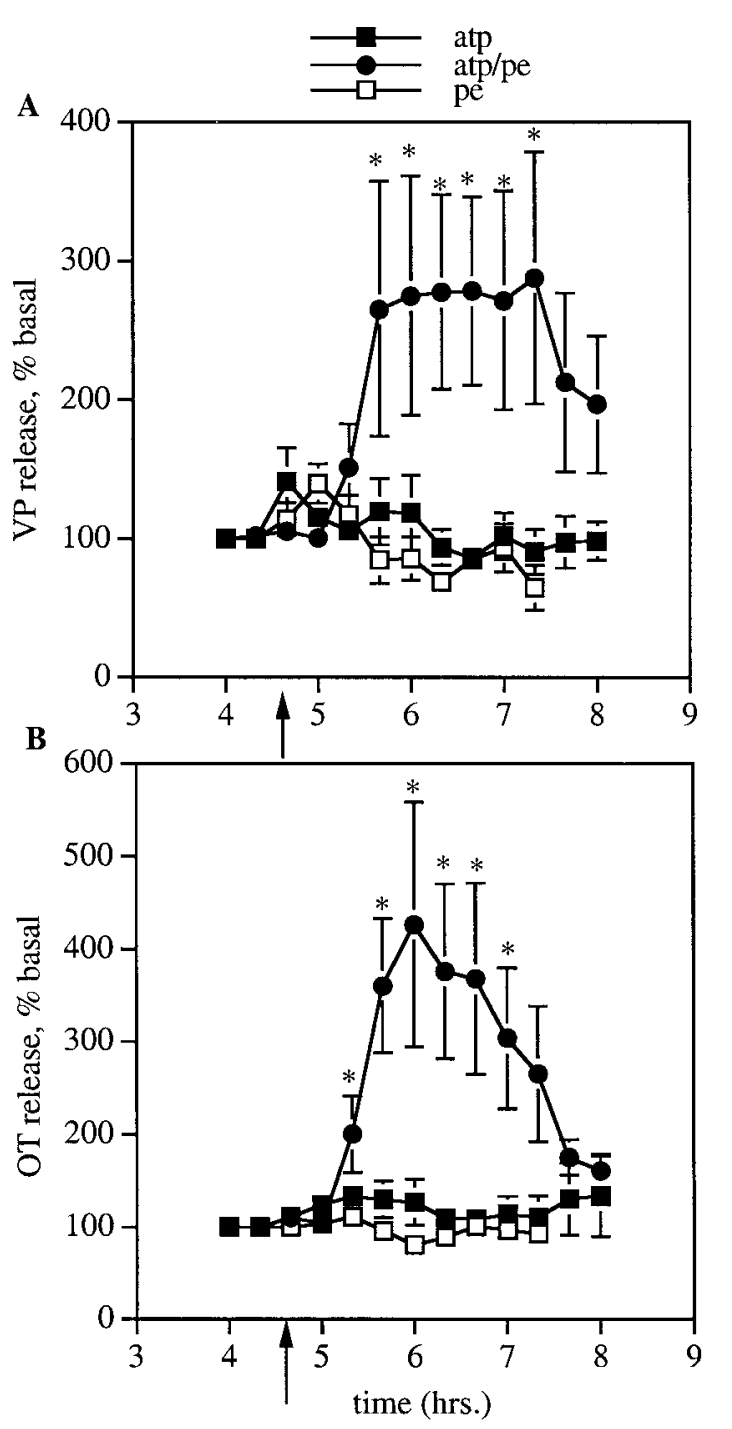

Figure 5. $A, \mathrm{VP}$ release in response to simultaneous exposure to ATP $(100$ $\mu \mathrm{M})$ and PE $(100 \mu \mathrm{M})$. The fast and unsustained effects of ATP (see Fig. 2) or PE (from Fig. 4) on VP release are dwarfed by the augmented and sustained stimulation of VP release obtained by simultaneous exposure to ATP and PE $(* p \leq 0.002)$. The synergistic response was delayed by $\sim 40$ min compared with peak responses observed with ATP $(100 \mu \mathrm{M})$ or PE (100 $\mu \mathrm{M})$ individually. Basal release for ATP plus PE $(n=12)$, ATP $(n=14)$, and PE $(n=11)$ groups was $31.5 \pm 4.9,42.6 \pm 8.5$, and $35.1 \pm 14.1 \mathrm{pg} / \mathrm{ml}$, respectively. $B$, OT release in response to simultaneous exposure to ATP $(100 \mu \mathrm{M})$ and PE $(100 \mu \mathrm{M})$. ATP and PE result in a synergistic stimulation of OT release when compared with the fast and unsustained effects of ATP (see Fig. 3) or the lack of an effect of PE on OT release $\left({ }^{*} p \leq 0.002\right)$. Basal release for ATP plus PE $(n=8)$, ATP $(n=11)$, and PE $(n=12)$ groups was $67.8 \pm 19.8,87.8 \pm 24.4$, and $87 \pm 25.6 \mathrm{pg} / \mathrm{ml}$, respectively. Explants were exposed to ATP and/or PE beginning at the time indicated by the arrow. pe, PE.

\section{Role of the $\mathbf{P}_{2 \mathrm{X}}$ receptor, $\mathrm{PKC}$, and gene transcription in the synergism}

To determine whether the $\mathrm{P}_{2 \mathrm{X}}$ receptor is involved in the synergism, explants were exposed to PPADS $(10 \mu \mathrm{M})$, ATP $(100 \mu \mathrm{M})$, and PE $(100 \mu \mathrm{M})$. As Figure 6 demonstrates, there was a statistically significant inhibition of the synergistic response in the explants perifused with PPADS, ATP, and PE when compared with explants exposed to ATP and PE without PPADS $(F=23.724 ; p=$ 0.0009). As shown in Figure 7, PPADS had no effect on PEmediated VP responses. PE still elicited a rapid increase in VP release in the presence of PPADS. These data, in conjunction with that in Figure 2, indicate that activation of the $\mathrm{P}_{2 \mathrm{X}}$ receptor is required both for increases in $\mathrm{VP}$ release elicited by ATP alone

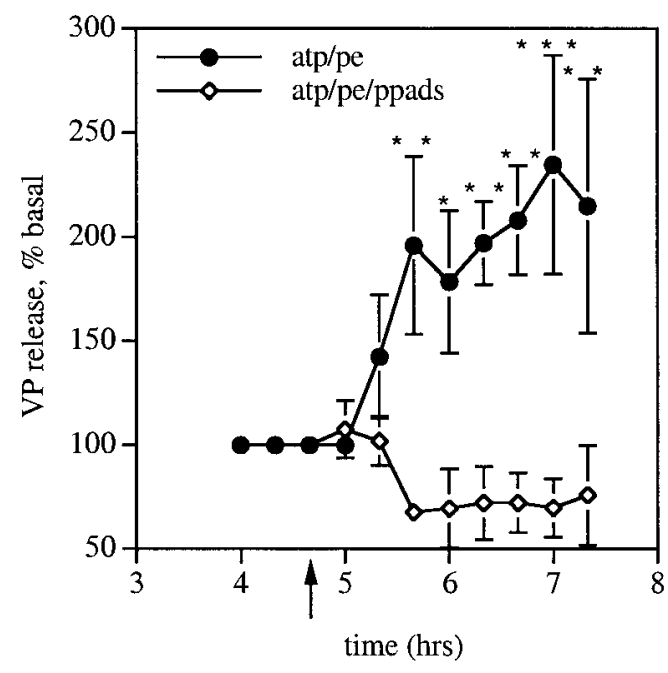

Figure 6. Inhibition of the ATP plus PE-mediated synergistic increase in VP release by PPADS. PPADS $(10 \mu \mathrm{M})$ blocked the VP response to ATP $(100 \mu \mathrm{M})$ plus PE $(100 \mu \mathrm{M})(F=23.724 ; p=0.0009)$. Explants were exposed to ATP plus PE beginning at the time indicated by the arrow. Thus, activation of the $P_{2 X}$ receptors is required for the synergism observed when explants are exposed to the combination of ATP and PE. The delayed and sustained stimulation of VP release shown in Figure 5 is replicated in this group of explants exposed to ATP plus PE in the absence of PPADS. Basal release for ATP plus PE $(n=5)$ and ATP, PE, plus PPADS $(n=6)$ groups was $37.9 \pm 12.5$ and $38.8 \pm 20.05 \mathrm{pg} / \mathrm{ml}$, respectively $\left({ }^{* * *} p \leq 0.0001 ; * * p \leq\right.$ $\left.0.001 ;{ }^{*} p \leq 0.002\right)$.

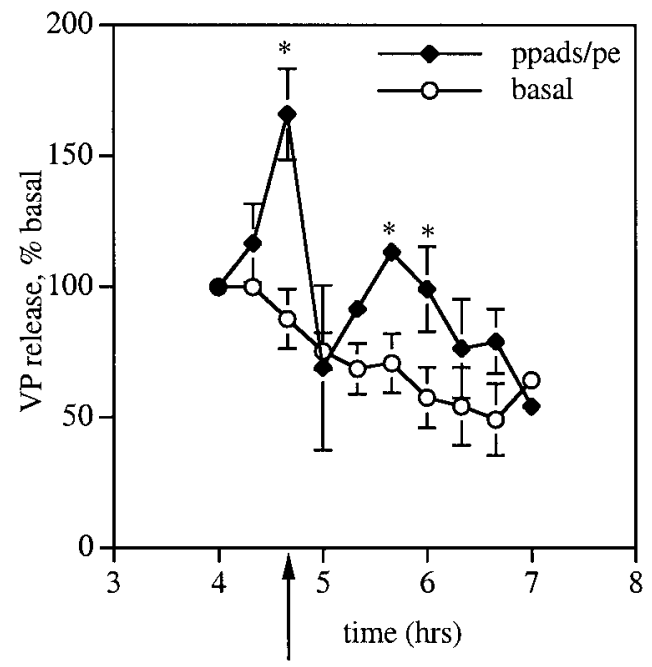

Figure 7. Effect of PPADS on PE-mediated VP release. PPADS $(10 \mu \mathrm{M})$ did not block the VP response to PE $(100 \mu \mathrm{M})(F=7.269 ; p=0.0308)$. Explants were exposed to PE beginning at the time indicated by the arrow. Basal release for PPADS plus PE $(n=5)$ and control $(n=4)$ groups was $75.14 \pm 29.67$ and $76.26 \pm 57 \mathrm{pg} / \mathrm{ml}$, respectively $\left({ }^{*} p<0.05\right)$.

and for the synergistic response elicited by combined exposure to ATP and PE.

Because $\alpha_{1}$ receptors are coupled to $\mathrm{PKC}$ via the phospholipase $\mathrm{C}$ (PLC) cascade, the role of PKC in the synergistic response of PE and ATP was evaluated using the cell-permeable PKC inhibitor BI. Explants were perifused with BI $(1 \mu \mathrm{M})$ for $30 \mathrm{~min}$ before the addition of ATP $(100 \mu \mathrm{M})$ and PE $(100 \mu \mathrm{M})$ to the perifusate. As shown in Figure 8, BI significantly inhibited the sustained response observed with ATP and PE $(F=7.533 ; p=0.0133)$. BI did not affect basal VP release $(F=0.393 ; p=0.5481$; data not shown). This demonstrates a requirement for PKC activation in the synergistic response.

The ATP plus PE-mediated synergism was delayed by $\sim 40 \mathrm{~min}$ after exposure to ATP and PE. Because this delay is sufficient to 


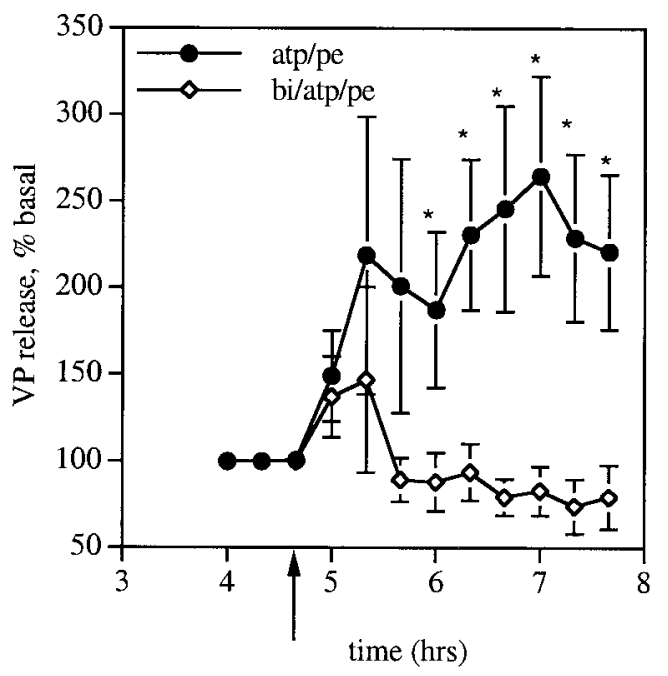

Figure 8. Effect of the PKC inhibitor $(1 \mu \mathrm{M} \mathrm{BI})$ on ATP plus PE-mediated $V P$ release. Addition of the PKC inhibitor blocked VP responses to ATP $(100 \mu \mathrm{M})$ plus PE $(100 \mu \mathrm{M})(F=7.533 ; p=0.0133)$. Note that the small and unsustained increase in VP release characteristic of the response to ATP alone is evident in the group receiving ATP plus PE with BI. Explants were exposed to ATP plus PE beginning at the time indicated by the arrow. Basal release for ATP plus PE $(n=14)$ and ATP, PE, plus BI $(n=6)$ groups was $102.21 \pm 13.69$ and $100.97 \pm 23.6 \mathrm{pg} / \mathrm{ml}$, respectively $\left({ }^{*} p<0.045\right) . b i$, BI.

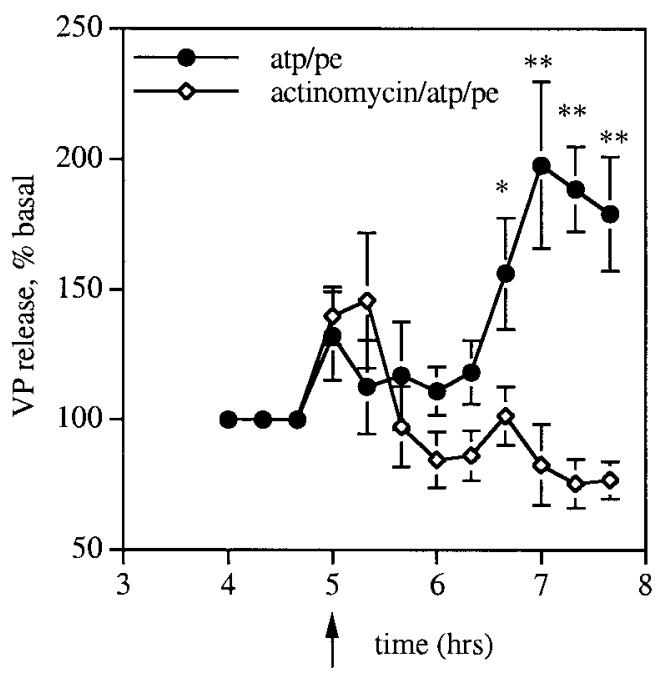

Figure 9. Effect of the inhibitor of gene transcription $(10 \mu \mathrm{g} / \mathrm{ml}$ actinomycin) on ATP plus PE-mediated VP release. Addition of the inhibitor blocked VP responses to ATP $(100 \mu \mathrm{M})$ plus PE $(100 \mu \mathrm{M})(F=12.391 ; p=$ $0.0065)$. Explants were exposed to ATP plus PE beginning at the time indicated by the arrow. Basal release for ATP plus PE $(n=5)$ and actinomycin, ATP, plus PE $(n=6)$ groups was $73.9 \pm 37$ and $68.9 \pm 34.5$ $\mathrm{pg} / \mathrm{ml}$, respectively $\left({ }^{*} p=0.019 ;{ }^{* *} p<0.0001\right)$.

allow for new protein synthesis, the involvement of gene transcription was evaluated using actinomycin, an inhibitor of gene transcription. Previous studies demonstrated that a $2 \mathrm{hr}$ exposure of HNS explants to actinomycin did not affect basal VP release and did not interfere with cAMP stimulation of VP release (Song et al., 1998). As shown in Figure 9, explants perifused with actinomycin $(10 \mu \mathrm{g} / \mathrm{ml})$, which were also exposed to ATP and PE, did not respond with a synergistic increase in VP. This supports the hypothesis that gene transcription is required for the induction of the synergism.

\section{DISCUSSION}

Information about decreases in blood volume and pressure associated with moderate hemorrhage is monitored by volume and baroreceptors in the atria and carotid sinus and transmitted to the
A1 catecholamine neurons in the caudal ventrolateral medulla by way of the nucleus tractris solitarius (Raby and Renaud, 1989; Smith et al., 1995). The A1 neurons then synapse directly on and stimulate VP neurons in the SON and PVN (Alonso and Assenmacher, 1984; Day and Renaud, 1984; Day et al., 1984, 1992; Shioda et al., 1992; Ginsberg et al., 1994; Smith et al., 1995). Thus, the A1 pathway represents one of the final relays for transmission of hemodynamic regulatory information from the periphery to the magnocellular VP neurons. Pharmacological evidence supports a role for ATP as the chemical transmitter for this pathway, and hypothalamic synaptosomes release ATP after depolarization (Fredholm and Vernet, 1979; Potter and White, 1980). Furthermore, ATP and $\left[{ }^{3} \mathrm{H}\right]$ noradrenaline release experiments from rat hypothalamic slices demonstrated that a significant component of ATP and NE is coreleased from nerve terminals of the A1 catecholaminergic cell group (Sperlagh et al., 1998). This is similar to the peripheral nervous system in which ATP is colocalized with $\mathrm{NE}$ in synaptic vesicles in the sympathetic nervous system (Whittaker, 1982; Geffen and Livett, 1996). It is released after physiological nerve activity (Sperlagh and Vizi, 1996) and functions as a cotransmitter with $\mathrm{NE}$ in a number of tissues innervated by the sympathetic system (Burnstock, 1990; von Kugelgen and Starke, 1991). Thus, central noradrenergic neurons might use similar cotransmission. Indeed, there is abundant expression of $\mathrm{P}_{2}$ purinoceptors in the CNS, and a high density of receptors exists in the hypothalamus (Balcar et al., 1995). Mounting evidence supports the hypothesis that noradrenergic pathways of the CNS use purinergic transmission (Day et al., 1993; Chen et al., 1994; Illes et al., 1996). The neurohypophyseal system is a useful model for neuronal function. Therefore, the present findings on the role of purinergic-adrenergic cotransmission in the regulation of VP release provide insights into the importance of putative purinergic-adrenergic cotransmission in other CNS pathways.

Several purinergic receptor types have been cloned. The $\mathrm{P}_{1}$ purinoceptors are responsive to adenosine and AMP, whereas the $\mathrm{P}_{2}$ purinoceptors are responsive to ATP (Zimmerman, 1994). Subtypes of the $\mathrm{P}_{2}$ receptors include $\mathrm{P}_{2 \mathrm{X}}, \mathrm{P}_{2 \mathrm{Y}}, \mathrm{P}_{2 \mathrm{U}}, \mathrm{P}_{2 \mathrm{~T}}, \mathrm{P}_{2 \mathrm{D}}$, and $\mathrm{P}_{2 Z}$. The $\mathrm{P}_{2 \mathrm{X}}$ type is a ligand-gated ion channel permeable to $\mathrm{Na}^{+}$, $\mathrm{K}^{+}$, and $\mathrm{Ca}^{+}$, whereas the $\mathrm{P}_{2 \mathrm{Y}}, \mathrm{P}_{2 \mathrm{U}}$, and $\mathrm{P}_{2 \mathrm{~T}}$ receptors are G-protein-linked receptors coupled to phospholipase $\mathrm{C}$ and inositol triphosphate formation (Chen et al., 1995). These receptors are differentiated by ligand selectivity, with UTP activating the $\mathrm{P}_{2 \mathrm{U}}$ receptors and $\mathrm{P}_{2 \mathrm{~T}}$ responding to ADP. Multiple $\mathrm{P}_{2}$ purinoceptors are expressed in the CNS. The hypothalamus is one of the most densely labeled structures. Both $\mathrm{P}_{2 \mathrm{X}}$ and $\mathrm{P}_{2 \mathrm{U}}$ receptors have been demonstrated electrophysiologically on SON neurons (Hiruma and Bourque, 1995), and mRNA for five of the seven $\mathrm{P}_{2 \mathrm{x}}$ receptor subtypes is expressed in the SON (Shibuya et al., 1998). PPADS, an antagonist of $\mathrm{P}_{2}$ receptors (Lambrecht, 1996), blocked electrical responses to ATP, but not UTP, in rat magnocellular neurosecretory cells of the SON (Hiruma and Bourque, 1995). It also blocked ATP stimulation of VP release, confirming a role for the $\mathrm{P}_{2 \mathrm{X}}$ receptor.

The ATP-mediated rapid, but unsustained, increase in VP release is consistent with activation of ligand-gated ion channels that desensitize. The restoration of the ATP response after a washout period is consistent with receptor desensitization. Furthermore, the decay is unlikely to reflect depletion of releasable VP stores, because in other experiments, explants retained elevated VP release throughout $6 \mathrm{hr}$ of perif usion with $25 \mathrm{~mm} \mathrm{KCl}$ (Ludwig et al., 1997). In electrophysiological studies, some SON neurons showed little-to-moderate desensitization, whereas others showed strong desensitization (Shibuya et al., 1998).

Multiple sites of action for ATP exist in the explant. A direct action on VP neurons is likely because these neurons express $\mathrm{P}_{2 \mathrm{X}}$ mRNA (Shibuya et al., 1998) and application of $P_{2 x}$ agonists elicits TTX-insensitive depolarizations (Hiruma and Bourque, 1995) and increases in intracellular $\left[\mathrm{Ca}^{2+}\right]$ in dissociated SON neurons (Shibuya et al., 1998). Additionally, ATP may activate other neurons afferent to the VP neurons, and it may act on VP terminals in 


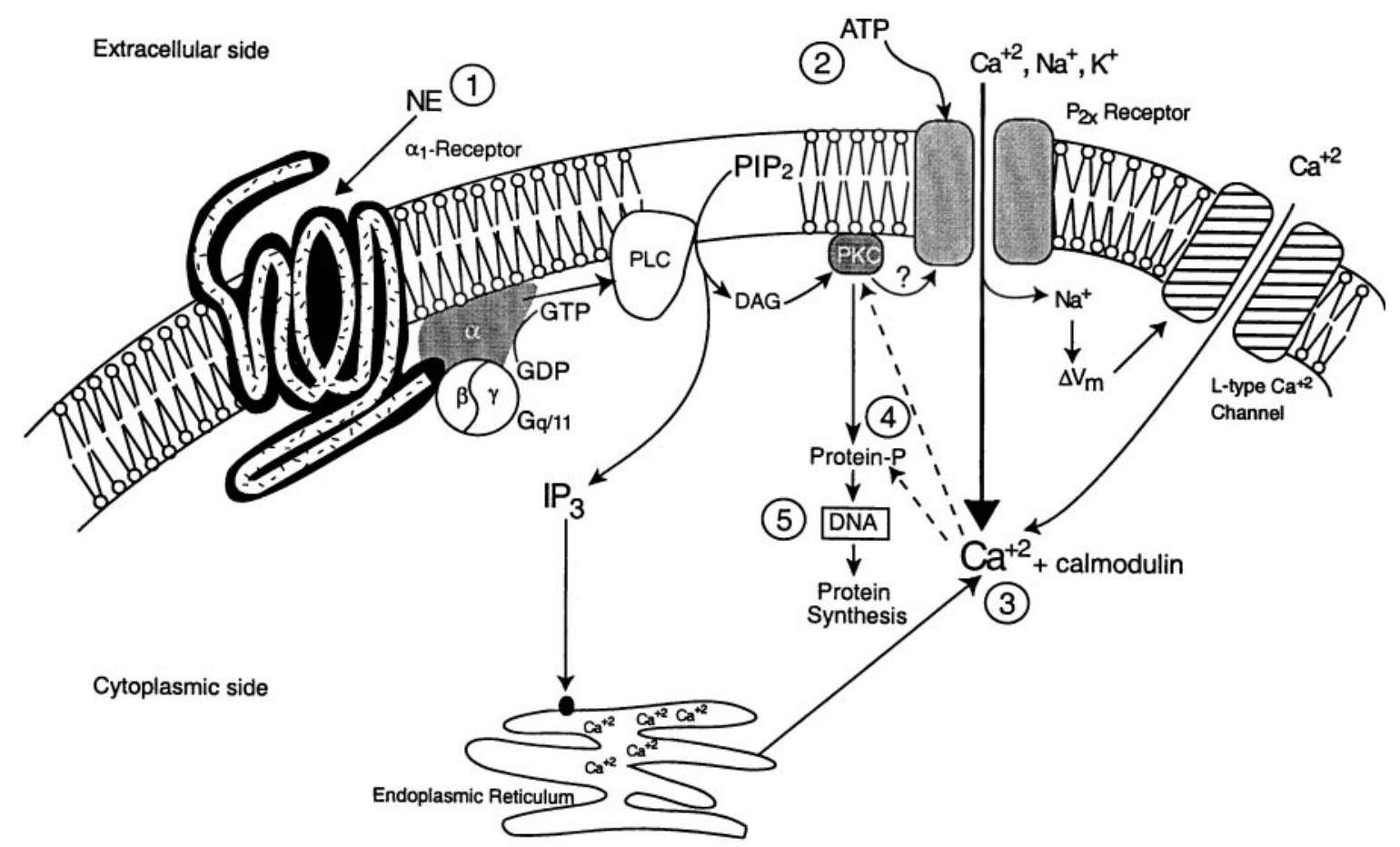

Figure 10. Schematic diagram showing possible points of convergence of intracellular signaling cascades that might lead to NE plus ATP-mediated synergism. 1 , NE activates the $\alpha_{1}$ receptor, which is coupled to $\mathrm{G}_{\mathrm{s} 11}$-protein. Activation of the receptor triggers an exchange of GDP for GTP. The trimeric G-protein then dissociates into $\alpha$ and $\beta / \gamma$ dimer. The GTP-bound form of the $\alpha$ and/or $\beta / \gamma$ subunit then activates the PLC/IP $/$ PKC pathway. 2 , ATP binds to the $\mathrm{P}_{2 \mathrm{X}}$ receptor resulting in the opening of a nonspecific ion channel. 3 , Both of these events increase intracellular Ca ${ }^{2+}$. Activation of the $\mathrm{IP}_{3}$ branch of the PLC pathway releases intracellular $\mathrm{Ca}^{2+}$ from the endoplasmic reticulum. Activation of $\mathrm{P}_{2 \mathrm{X}}$ receptors allows $\mathrm{Ca}{ }^{2+}$ entry through the $\mathrm{P}_{2 \mathrm{X}}$ channel. In addition, $\mathrm{Na}^{+}$influx through the channel depolarizes the membrane, probably opening voltage-sensitive $\mathrm{Ca}^{2+}$ channels and further increasing $\mathrm{Ca}^{2+}$ influx. Thus, increased intracellular $\mathrm{Ca}^{2+}$ represents one major point of convergence. 4 , The increase in intracellular $\mathrm{Ca}^{2+}$ increases the activity of kinases. Specifically, because PKC is $\mathrm{Ca}^{2+}$ dependent, higher internal $\mathrm{Ca}^{2+}$ levels increase the activity of PKC. Increases in PKC activity might lead to phosphorylation of the ATP-dependent $\mathrm{P}_{2 \mathrm{X}}$ ion channel, leading to a higher open probability for the channel. $5, \mathrm{PKC}$ and/or $\mathrm{Ca}{ }^{2+} / \mathrm{calmodulin}^{\mathrm{may}}$ phosphorylate transcription factors, thereby inducing transcription of other transcription factors (such as immediate-early genes) or perhaps additional receptors. The observed delay of $\sim 40 \mathrm{~min}$ before the onset of the synergistic response as well as the inhibition of the synergism by actinomycin indicates that this final step is a requirement for synergism. $P I P_{2}$, Phosphatidylinositol 4,5-bisphosphate.

the neural lobe. ATP is released from the neural lobe in a stimulusdependent manner (Sperlagh et al., 1999), is costored with neuropeptides in the secretory granules of neurohypophyseal nerve endings in millimolar concentrations (Gratzl et al., 1980), and increases VP, but not OT, release from the isolated neurohypophyseal terminals (Troadec et al., 1998). Although this effect of ATP may have contributed to the VP responses observed in the current experiments, the fact that OT release was also stimulated indicates that this is not the only site of ATP action. Thus, the actions of ATP on HNS explants can be attributed at least in part to actions at the VP cell body.

Coactivation of purinergic and $\alpha_{1}$-adrenergic receptors resulted in a response that was dramatically different from the responses achieved from the individual exposures to either ATP or phenylephrine. It was severalfold larger and sustained for several hours. Several intracellular mechanisms might underlie the synergistic increase in VP release. The first is recruitment of additional purinoceptor subtypes. This was considered feasible, because functional $\mathrm{P}_{2 \mathrm{U}}$ receptors have been demonstrated electrophysiologically on SON neurons (Hiruma and Bourque, 1995). Because these receptors couple to the same class of G-proteins as the $\alpha$-adrenergic receptors $\left[\mathrm{G}_{\mathrm{q} / 11}\right.$ (Zimmerman, 1994)], it seemed possible that previously undetected activation of these receptors amplified $\alpha$-adrenergic-mediated activation of the PLC-PKC signal cascade. However, this possibility was eliminated by the finding that PPADS, which does not block $\mathrm{P}_{2 \mathrm{U}}$ receptors, prevented the ATP plus PE-mediated synergism (Hiruma and Bourque, 1995). A second possibility is that the synergism results from convergence of the intracellular signaling cascades initiated by simultaneous opening of the $\mathrm{P}_{2 \mathrm{X}}$-gated ion channel and activation of the PLC cascade by PE. As shown in Figure 10, both signal transduction pathways increase intracellular $\mathrm{Ca}^{2+}$, and this in turn activates $\mathrm{PKC}$ as well as other $\mathrm{Ca}^{2+}$-dependent kinases. Thus, intracellular $\mathrm{Ca}^{2+}$ may be central to the augmentation phenomenon. Blockade of the synergism by the PKC inhibitor supports a central role for $\mathrm{Ca}^{2+}$. dependent phosphorylation in the synergism. A third possibility is that PKC-induced phosphorylation of the ATP-gated ion channels changes conductance of the channel (Tien et al., 1994; Idriss et al., 2000) or decreases receptor desensitization. Although this is an intriguing possibility, it is not an adequate explanation for the synergism, because phosphorylation events occur within seconds to minutes, but the ATP and PE synergism was delayed by $\sim 40 \mathrm{~min}$. This delay is long enough to allow for new protein synthesis. Blockade of the synergism by actinomycin demonstrates its dependence on new protein synthesis. This could occur as a result of $\mathrm{Ca}^{2+}$-dependent phosphorylation of transcription factors. New synthesis of receptors is one possible mechanism of synergism that might require gene transcription.

In addition to the above intracellular mechanisms, modulation of local afferents by either ATP or PE could contribute to the synergism. For example, application of NE to hypothalamic slices increases the frequency of EPSPs in PVN magnocellular neurons (Daftary et al., 1998). Similarly, inhibition of inhibitory afferents could lead to a potentiated response. However, these mechanisms would be activated rapidly and therefore are not solely responsible for the delayed synergism.

The synergistic effect of ATP and PE is likely to have physiological significance for the hemodynamic regulation of VP release, because corelease of transmitters may be required to achieve maximal and sustained increases in plasma VP in response to decreases 
in blood pressure or chronic hypotension. Thus, the colocalized substances may reflect the need for rapid release of VP, while promoting sustained increases in VP. This study provides the first demonstration of a synergistic effect of purinergic-adrenergic cotransmission on $\mathrm{VP}$ release. It may also provide insight into the role of purinergic cotransmission at other synapses in the hypothalamus and throughout the CNS. The A1 cell group contributes up to $60 \%$ of the total noradrenergic input to the whole hypothalamus (Palkovitis, 1981; Pacak et al., 1995), and the synergistic effect of ATP and PE on OT release demonstrates that the phenomenon is not limited to VP neurons. ATP may be coreleased with norepinephrine from locus coeruleus neurons (Shen and North, 1993). Putative purinergic-noradrenergic cotransmission by locus coeruleus neurons might have profound effects on the CNS, because they are associated with receiving and distributing information from and to sites associated with a number of motor, sensory, and behavioral functions. ATP is also stored and released with other neurotransmitters, including acetylcholine, nitric oxide, neuropeptide $\mathrm{Y}$, substance $\mathrm{P}$, and vasoactive intestinal peptide (Sneddon et al., 1999). The identification of extensive $\mathrm{P}_{2 \mathrm{X}}$ receptor immunoreactivity and mRNA distribution throughout the CNS further supports a role for extracellular ATP in processes such as sensory transmission and sensory-motor integration and in neuronal phenomenon such as long-term potentiation and depression (Kanjhan et al., 1999). Thus, the current demonstration of purinergic and adrenergic synergism on VP release suggests functional ramifications of ATP cotransmission throughout the CNS.

\section{REFERENCES}

Alonso G, Assenmacher I (1984) Ultrastructural analysis of the noradrenergic innervation of rat supraoptic nucleus. Neurosci Lett 49:45-50.

Balcar VJ, Li Y, Killinger S, Bennett MR (1995) Autoradiography of P2x ATP receptors in rat brain. Br J Pharmacol 115:302-306.

Beroukas D, Willoughby JO, Blessing WW (1989) Neuropeptide Y-like immunoreactivity is present in boutons synapsing on vasopressincontaining neurons in rabbit supraoptic nucleus. Neuroendocrinology 50:222-228.

Bittencourt JC, Benoit R, Sawchenko PE (1991) Distribution and origins of substance P-immunoreactive projections to the paraventricular and supraoptic nuclei: partial overlap with ascending catecholaminergic projections. J Chem Neuroanat 4:63-78.

Blessing WW, Howe PRC, Joh TH, Oliver JR, Willoughby JO (1986) Distribution of tyrosine hydroxylase and neuropeptide Y-like immunoreactive neurons in rat medulla oblongata, with attention to colocalization studies, presumptive adrenaline-synthesizing perikarya, and vagal pre-ganglionic neurons. J Comp Neurol 248:285-300.

Burnstock G (1990) Noradrenaline and ATP as cotransmitters in sympathetic nerves. Neurochem Int 17:357-368.

Chen ZP, Levy A, Lightman SL (1994) Activation of specific ATP receptors induces a rapid increase in intracellular calcium ions in rat hypothalamic neurons. Brain Res 641:249-256.

Chen Z-P, Levy A, Lightman SL (1995) Nucleotides as extracellular signalling molecules. J Neuroendocrinol 7:83-96.

Daftary S, Boudaba C, Szabo K, Tasker J (1998) Noradrenergic excitation of magnocellular neurons in the rat hypothalamic paraventricular nucleus via intranuclear glutamatergic circuits. J Neurosci 18:10619-10628.

Day TA, Renaud LP (1984) Electrophysiological evidence that noradrenergic afferents selectively facilitate the activity of supraoptic vasopressin neurons. Brain Res 303:233-240.

Day TA, Ferguson AV, Renaud LP (1984) Facilitatory influence of noradrenergic afferents on the excitability of rat paraventricular nucleus neurosecretory cells. J Physiol (Lond) 355:237-249.

Day TA, Randle JCR, Renaud LP (1985) Opposing alpha- and betaadrenergic mechanisms mediate dose-dependent actions of noradrenaline on supraoptic vasopressin neurons in vivo. Brain Res 358:171-179.

Day TA, Renaud LP, Sibbald JR (1990) Excitation of supraoptic vasopressin cells by stimulation of the A1 noradrenaline cell group: failure to demonstrate role for established adrenergic or amino acid receptors. Brain Res 516:91-98.

Day TA, Sibbald JR, Smith DW (1992) A1 neurons and excitatory amino acid receptors in rat caudal medulla mediate vagal excitation of supraoptic vasopressin cells. Brain Res 594:244-252.

Day TA, Sibbald JR, Khanna S (1993) ATP mediates an excitatory noradrenergic neuron input to supraoptic vasopressin cells. Brain Res 607:341-344.

Everitt BJ, Hokfelt T, Terenius L, Tatemoto K, Mutt V, Goldstein M (1984) Differential coexistence of neuropeptide Y (NPY)-like immunoreactivity with catecholamines in the central nervous system of the rat. Neuroscience 11:443-462.

Fredholm B, Vernet L (1979) Release of tritium nucleotides from ${ }^{3} \mathrm{H}-$ adenine labelled hypothalamic synaptosomes. Acta Physiol Scand 106:97-107.

Fried G (1980) Small noradrenergic storage vesicles isolated from rat vas deferens-biochemical and morphological characterization. Acta Physiol Scand Suppl 493:1-28.

Gartside SE, Suaud-Chagny MF, Tappaz M (1995) Evidence that activation of the hypothalamo-pituitary-adrenal axis by electrical stimulation of the noradrenergic A1 group is not mediated by noradrenaline. Neuroendocrinology 62:2-12.

Geffen LB, Livett BG (1996) Synaptic vesicles in sympathetic neurons. Physiol Rev 51:98-157.

Ginsberg SD, Hof PR, Young WG, Morrison JH (1994) Noradrenergic innervation of vasopressin- and oxytocin-containing neurons in the hypothalamic paraventricular nucleus of the macaque monkey: quantitative analysis using double-label immunohistochemistry and confocal laser microscopy. J Comp Neurol 341:476-491.

Gratzl M, Todd-Pedersen C, Daett D, Treiman M, Thorn N (1980) Isolation and characterization of secretory granules from bovine neurohypophyses. Hoppe Seylers Z Physiol Chem 361:1615-1628.

Hiruma H, Bourque CW (1995) P2 purinoceptor-mediated depolarization of rat supraoptic neurosecretory cells in vitro. J Physiol (Lond) 489:805-811.

Idriss H, Hannun Y, Boulpaep E, Basavappa S (2000) Regulation of volume-activated chloride channels by P-glycoprotein: phosphorylation has the final say! J Physiol (Lond) 524:629-636.

Illes P, Nieber K, Norenberg W (1996) Electrophysiological effects of ATP on brain neurons. J Auton Pharmacol 16:407-411.

Kanjhan R, Housley G, Burton L, Christie D, Kippenberger A, Thorne P, Luo L, Ryan A (1999) Distribution of the P2x2 receptor subunit of the ATP-gated ion channels in the rat central nervous system. J Comp Neurol 407:11-32.

Lambrecht G (1996) Design and pharmacology of selective P2purinoceptor antagonists. J Auton Pharmacol 6:341-344.

Ludwig M, Morris M, Sladek CD (1997) Effects of antisense oligodeoxynucleotides on peptide release from hypothalamoneurohypophyseal explants. Am J Physiol 272:R1441-R1446.

Lundberg JM, Pernow J, Lacroix JS (1989) Neuropeptide Y: sympathetic cotransmitter and modulator? News Physiol Sci 4:13-17.

Pacak K, Palkovitis M, Kopin IJ, Goldstein DS (1995) Stress-induced norepinephrine release in the hypothalamic paraventricular nucleus and pituitary-adrenocortical and sympathoadrenal activity: in vivo microdialysis studies. Front Neuroendocrinol 16:89-150.

Palkovitis M (1981) Cathecholamines in the hypothalamus: an anatomical review. Neuroendocrinology 33:123-128.

Potter P, White TD (1980) Release of ATP from synaptosomes from different regions of rat brain. Neuroscience 5:1351-1356.

Raby WN, Renaud LP (1989) Dorsomedial medulla stimulation activates rat supraoptic oxytocin and vasopressin neurons through different pathways. J Physiol (Lond) 417:279-294.

Sawchenko PE, Swanson LW, Grzanna R, Howe PRC, Polak JM, Bloom SR (1985) Co-localization of neuropeptide-Y immunoreactivity in brainstem catecholaminergic neurons that project to the paraventricular nucleus of the hypothalamus. J Comp Neurol 241:138-153.

Shen K, North R (1993) Excitation of rat locus coeruleus neurons by adenosine $5^{\prime}$-triphosphate: ionic mechanism and receptor characterization. J Neurosci 13:894-899.

Shibuya I, Tanaka K, Hattori Y, Uezono Y, Nobuya H, Noguchi J, Ueta Y, Izumi F, Yamashita H (1998) Evidence that multiple P2x purinoceptors are functionally expressed in rat supraoptic neurones. J Physiol (Lond) 514:351-367.

Shioda S, Shimoda Y, Nakai Y (1992) Ultrastructural studies of medullary synaptic inputs to vasopressin-immunoreactive neurons in the supraoptic nucleus of the rat hypothalamus. Neurosci Lett 148:155-158.

Sladek C, Yagil C (1990) Diverse effects of norepinephrine on vasopressin release may reflect modulation by hypotonicity. J Neuroendocrinol 2:363-367.

Sladek CD, Armstrong WE (1987) $\gamma$-Aminobutyric acid antagonists stimulate vasopressin release from organ-cultured hypothalamoneurohypophyseal explants. Endocrinology 120:1576-1580.

Sladek CD, Knigge KM (1977) Cholinergic stimulation of vasopressin release from the rat hypothalamo-neurohypophyseal system in organ culture. Endocrinology 101:411-420.

Sladek CD, Blair ML, Chen YH, Rockhold RW (1986) Vasopressin and renin response to plasma volume loss in spontaneously hypertensive rats. Am J Physiol 250:H443-H452.

Smith DW, Sibbald JR, Khanna L, Day TA (1995) Rat vasopressin cell responses to stimulated hemorrhage: stimulus-dependent role for A1 noradrenergic neurons. Am J Physiol 268:R1336-R1342.

Sneddon P, Wetfall TD, Todorov LD, Todorov-Mihaylova S, Westfall DP, Kennedy C (1999) Modulation of purinergic neurotransmission. Prog Brain Res 120:11-19.

Song Z, Sidorowicz HE, Sladek CD (1998) Effect of actinomycin and cycloheximide on stimulation of vasopressin release by 8-Br-cAMP. FASEB J 12:A1034. 
Sperlagh B, Vizi ES (1996) Neuronal synthesis, storage, and release of ATP. Semin Neurosci 8:175-186.

Sperlagh B, Sershen H, Lajtha A, Vizi ES (1998) Co-release of endogenous ATP and $[3 \mathrm{H}]$ noradrenaline from rat hypothalamic slices: origin and modulation by $\alpha 2$-adrenoceptors. Neuroscience 82:511-520.

Sperlagh B, Mergl Z, Juranyi Z, Vizi E, Makara G (1999) Local regulation of vasopressin and oxytocin secretion by extracellular ATP in the isolated posterior lobe of the rat hypophysis. J Endocrinol 160:343-350.

Tien X, Brasitus T, Kaetzel M, Dedman J, Nelson D (1994) Activation of the cystic fibrosis transmembrane conductance regulator by cGMP in the human colonic cancer cell line, Caco-2. J Biol Chem 269:51-54.

Troadec J, Thirion S, Nicaise G, Lemos J, Dayanithi G (1998) ATP- evoked increases in $\left[\mathrm{Ca}^{2+}\right]_{i}$ and peptide release from isolated neurohypophysial terminals via a $\mathrm{P} 2 \times 2$ purinoceptor. J Physiol (Lond) 511:89-103.

von Kugelgen I, Starke K (1991) Noradrenaline-ATP co-transmission in the sympathetic nervous system. Trends Pharmacol Sci 12:319-324.

Whittaker VP (1982) The synaptic vesicle. Handbook Neurochem 7:41-69.

Yagil C, Sladek CD (1990) Osmotic regulation of vasopressin and oxytocin release is rate sensitive in the hypothalamoneurohypophyseal explants. Am J Physiol 258:R492-R500.

Zimmerman H (1994) Signalling via ATP in the nervous system. Trends Neurosci 17:420-426. 